\title{
Effects of dihydrotestosterone on adipose tissue measured by serial analysis of gene expression
}

\section{Bolduc, M Larose, M Yoshioka, P Ye, P Belleau, C Labrie, J Morissette, V Raymond, F Labrie and J St-Amand}

Molecular Endocrinology and Oncology Research Center, Laval University Medical Center, Department of Anatomy and Physiology, Université Laval, Québec, Canada

(Requests for offprints should be addressed to Jonny St-Amand, Director, SAGE Laboratory, Molecular Endocrinology and Oncology Research Center, Québec Genome Center, Laval University Medical Center (CHUL), 2705 Boul. Laurier, Ste-Foy (Québec) G1V 4G2, Canada; Email: Jonny.St-Amand @ crchul.ulaval.ca)

\begin{abstract}
Intra-abdominal fat accumulation is related to several diseases, especially diabetes and heart disease. Molecular mechanisms associated with this independent risk factor are not well established. Through the serial analysis of gene expression (SAGE) strategy, we have studied the transcriptomic effects of castration and dihydrotestosterone (DHT) in retroperitoneal adipose tissue of C57BL6 male mice. Approximately 50000 SAGE tags were isolated in intact and gonadectomized mice, as well as 3 and $24 \mathrm{~h}$ after DHT administration. Transcripts involved in energy metabolism, such as glyceraldehyde-3phosphate dehydrogenase, malic enzyme supernatant, fatty acid synthase, lipoprotein lipase, hormone-sensitive lipase and monoglyceride lipase, were upregulated by DHT. Transcripts involved in adipogenesis, and cell cycle and cell shape organization, such as DDX5, C/EBP $\alpha$, cyclin I, procollagen types I, III, IV, V and VI, SPARC and matrix metalloproteinase 2, were upregulated by DHT. Cell defense, division and signaling, protein expression and many novel transcripts were regulated by castration and DHT. The present results provide global genomic evidence for a stimulation of glycolysis, fatty acids and triacylglycerol production, lipolysis and cell shape reorganization, as well as cell proliferation and differentiation, by DHT. The novel transcripts regulated by DHT may contribute to identify new mechanisms involved in the action of sex hormones and their potential role in obesity.
\end{abstract}

Journal of Molecular Endocrinology (2004) 33, 429-444

\section{Introduction}

Obesity is a growing epidemic in many countries, especially in sedentary populations (Seidell 2000). Important health disorders, such as cardiovascular diseases, atherosclerosis, diabetes mellitus and cancer (Bray 1985, Kissebah et al. 1989, Calle et al. 2003), are associated with obesity. In fact, there is a correlation between the distribution of fat accumulation and health disorders (Despres et al. 1990, Vague 1956, Sheehan \& Jensen 2000). Sex hormones partly define the localization of fat accumulation. Men tend to gain fat in the abdominal region while women accumulate fat mainly in the gluteal-femoral area (Sjostrom et al. 1972). The male pattern of fat accumulation is more closely associated with health disorders (Vague 1956, Sheehan \& Jensen 2000). A link may thus exist between androgen levels, fat accumulation and fat distribution. However, until now, the global molecular effects of androgens on adipose tissue have not been elucidated.

With the advent of DNA microarrays (Schena et al. 1995) and serial analysis of gene expression (SAGE) (Velculescu et al. 1995), new possibilities arose for large-scale transcriptome analysis and comparison. Both techniques enable characterization of the transcriptome under multiple experimental conditions. DNA microarrays are restricted to known sequences and have some limitations in quantification (Novak et al. 2002). However, the SAGE method is highly quantitative and does not require previous knowledge of the sequences under study. This powerful strategy allows us to characterize the entire transcriptome and perhaps discover novel genes (Velculescu et al. 1997, St-Amand et al. 2001).

We have already presented the transcriptome of normal adipose tissue in mice (Bolduc et al. 2004). In 
the present study, using the SAGE strategy, we show the effects of castration and dihydrotestosterone (DHT), the most potent androgen, on adipose tissue of male mice. The transcripts involved in fat metabolism are discussed, as well as many transcripts involved in various functions modulated by androgens in this tissue. These findings constitute the first step towards a precise understanding of the molecular mechanisms involved in the physiological effects of androgens on adipose tissue.

\section{Materials and methods}

\section{Sample preparation}

Retroperitoneal adipose tissue was obtained from 10 male C57BL6 12-14-week-old mice per group, purchased from Charles River Canada Inc (St Constant, Canada). The animals had access to Lab Rodent Diet No. 5002 and water ad libitum. A sham gonadectomy was performed 7 days prior to organ collection for the intact group, while gonadectomy was performed at the same time for the three gonadectomized (GDX) groups. DHT $(0 \cdot 1 \mathrm{mg})$ was injected $3 \mathrm{~h}$ (DHT3h) and $24 \mathrm{~h}$ (DHT24h) prior to killing in groups 3 and 4 . The dose of DHT selected was the smallest dose that could restore the prostate weight of GDX mice to the level of intact mice. The control groups (intact and GDX) received vehicle solution $(0.4 \%(\mathrm{w} / \mathrm{v})$ Methocel A15LV Premium/ 5\% ethanol) instead of DHT. All animal experimentation was conducted in accord with accepted standards of humane animal care. The retroperitoneal adipose tissue was dissected between 0900 and $1215 \mathrm{~h}$. The samples from all mice of the same group were pooled to eliminate interindividual variations and to extract sufficient amount of mRNA. The tissues were stored at $-80^{\circ} \mathrm{C}$ until RNA extraction.

\section{Transcriptome analysis}

The SAGE method was performed as previously described (Velculescu et al. 1995, 1997, Kenzelmann \& Muhlemann 1999, St-Amand et al. 2001). Polyadenylated RNA was extracted with the mRNA direct kit (Dynal, Oslo, Norway), annealed with the biotin- $5^{\prime}-\mathrm{T}_{18}-3^{\prime}$ primer and converted to cDNA with the cDNA synthesis kit (Invitrogen). The resulting cDNA library was digested with NlaIII (anchoring enzyme), and the $3^{\prime}$ restriction fragments were isolated with streptavidin-coated magnetic beads (Dynal) and separated into two populations. Each population was ligated to one of the two annealed linker pairs and extensively washed to remove unligated linkers. The tag beside the most 3' NlaIII restriction site (CATG) of each transcript was released by digestion with BsmFI (tagging enzyme). The blunting kit from Takara Co. (Otsu, Japan) was used for the blunting and ligation of the two tag populations. The resulting ligation products containing the ditags were amplified by PGR with an initial denaturation step of $1 \mathrm{~min}$ at $95^{\circ} \mathrm{C}$, followed by 28 cycles of $20 \mathrm{~s}$ at $94{ }^{\circ} \mathrm{C}, 20 \mathrm{~s}$ at $60^{\circ} \mathrm{C}$ and $2 \mathrm{~s}$ at $72{ }^{\circ} \mathrm{C}$ with $27 \mathrm{bp}$ primers (St-Amand et al. 2001). Due to the low mRNA content of adipose tissue, a second PCR amplification was performed on the ditags for 14 cycles in order to enhance the size of the SAGE library without affecting the quantitative information required for group comparisons (Virlon et al. 1999). Each amplification was followed by acrylamide gel purification of the ditags. Finally, large-scale PCR was performed for eight cycles. The PGR product was digested with NlaIII, and the band containing the ditags was extracted from the acrylamide gel. The purified ditags were self-ligated to form concatemers. The concatemers of 500-1800 bp were isolated by agarose gel. The resulting DNA fragments were ligated into the SphI site of pUC19 and cloned into UltraMAX DH5aFT (Invitrogen). White colonies were screened by PCR to select long inserts for automated sequencing.

\section{Bioinformatic analysis}

All SAGE tag sequences were deposited in the GEO database at the National Centre for Biotechnology Information (NCBI). Sequence files were analyzed by the SAGEana program, a modification of SAGEparser (ftp://ftp.pbrc.edu/public/eesnyder/ SAGE/). Tags corresponding to linker sequences were discarded, and duplicate concatemers were counted only once. Identification of the transcripts was obtained by matching the $15 \mathrm{bp}$ (CATG + 11 bp tags) with the UniGene and GenBank databases. The matching procedure used was very restrictive since, in order to avoid the possibility of sequencing errors in the expressed sequence tags (EST) database, we did not consider the matches that were identified only once among 
Table 1 General descriptive information about the four SAGE libraries analyzed

\begin{tabular}{|c|c|c|c|c|c|}
\hline & & & GDX+DHT & & \\
\hline & Intact & GDX & $3 \mathrm{~h}$ & $24 \mathrm{~h}$ & Total \\
\hline Tags sequenced & 45996 & 45521 & 51658 & 49256 & 192431 \\
\hline Transcript species & 17660 & 19768 & 19207 & 24553 & 61931 \\
\hline Well-characterized transcripts (\%) & $3401(19)$ & $3388(17)$ & $4011(21)$ & $4985(20)$ & $8274(13)$ \\
\hline Partially characterized transcripts (\%) & $1872(11)$ & $1859(10)$ & $2005(11)$ & $2642(11)$ & $5472(9)$ \\
\hline Novel transcripts (\%) & $11783(67)$ & $13887(70)$ & $12542(65)$ & $16006(65)$ & $49798(76)$ \\
\hline Multiple matches (\%) & $604(3)$ & $634(3)$ & $649(3)$ & $920(4)$ & $1387(2)$ \\
\hline Tags detected more than once & 4332 & 4127 & 5143 & 5003 & 10136 \\
\hline Well-characterized transcripts (\%) & $1685(39)$ & $1580(38)$ & $2252(44)$ & $2301(46)$ & 3919 (39) \\
\hline Partially characterized transcripts (\%) & $656(15)$ & $600(15)$ & 715 (14) & $732(15)$ & $1545(15)$ \\
\hline Novel transcripts (\%) & $1659(38)$ & $1618(39)$ & $1805(35)$ & $1503(30)$ & 3947 (39) \\
\hline Multiple matches (\%) & $332(8)$ & $329(8)$ & $371(7)$ & $467(9)$ & $725(7)$ \\
\hline Transcript species expressed $>0.1 \%$ & 90 & 72 & 100 & 55 & 144 \\
\hline Well-characterized transcripts (\%) & $57(63)$ & $43(60)$ & $65(65)$ & $33(60)$ & $91(63)$ \\
\hline Partially characterized transcripts (\%) & $10(11)$ & $8(11)$ & $10(10)$ & $5(9)$ & $14(10)$ \\
\hline Novel transcripts (\%) & $10(11)$ & $12(17)$ & $9(9)$ & $7(13)$ & $20(14)$ \\
\hline Multiple matches (\%) & 13 (15) & 9 (12) & $16(16)$ & 10 (18) & 19 (13) \\
\hline
\end{tabular}

the numerous sequences of an UniGene cluster. Indeed, the chance of matches with EST containing sequencing errors drops dramatically when at least two EST are identified in a UniGene cluster for a given tag sequence. A minimum of one EST with a known polyA tail had to be in the UniGene cluster to identifiy the last NlaIII site on the corresponding cDNA. Classification of the genes was based upon the updated information of the genome directory (Adams et al. 1995) found at the TIGR website (www.tigr.org/). To analyze the promoter sequences for the presence of hormone-responsive elements (HRE), the $2 \mathrm{~kb}$ upstream regions of the annotated transcription start of the differentially expressed transcripts were extracted from the mouse genome at NCBI (build 32, version 1). With a Perl script, the promoter sequences were parsed to find the occurrence and positions of the sequences TGTTCT and AGAACA, which are present in more than one natural androgen-responsive elements (Nelson et al. 1999). When the genes were on the minus strand of the mouse genome, the downloaded sequences were transformed into their reverse-complement before the parsing procedure.

\section{Statistical analysis}

We used the comparative count display (CGD) test to identify the transcripts that were differentially expressed significantly $(P \leq 0 \cdot 05)$ between the groups with more than a twofold change. The CCD test makes a key-by-key comparison of two key-count distributions by generating a probability that the frequency of any key in the distribution differs by more than a given fold factor from the other distribution. This statistical test has been described elsewhere (Lash et al. 2000). The data are normalized to 50000 tags in order to facilitate visual comparison in the tables.

\section{Results}

Four libraries (intact, GDX, GDX+DHT3h and GDX+DHT24h) were generated to characterize the effects of castration and DHT on adipose tissue transcriptome. Approximately 50000 tags were sequenced in each group for a total of 192431 tags. Thus, 61931 different transcript species were detected. The majority of the tags sequenced represent novel transcripts. However, most of the transcript species expressed at high levels correspond to transcripts of known genes (Table 1). The 196 well-characterized transcripts differentially expressed at a significant level $(P \leq 0.05)$ are presented in Tables 2-8, according to their functions. There were 117 transcripts upregulated 
Table 2 Differentially expressed transcripts involved in sugar and lipid metabolism

\begin{tabular}{|c|c|c|c|c|c|}
\hline Tags & I & G & $3 \mathrm{~h}$ & $24 \mathrm{~h}$ & Description (UniGene, Genbank) TGTTCT/AGAACA \\
\hline \multicolumn{6}{|l|}{ Sugar } \\
\hline ССТАСТАACCA & 61 & 48 & $228^{*}$ & 45 & $\uparrow$ aldolase $1, \mathrm{~A}$ isoform (Mm. 16763, BC043026) $)^{-179 /}$ \\
\hline CAAAAATAAAA & 0 & 2 & 1 & $25^{*}$ & $\uparrow$ enolase 1 , alpha non-neuron $(\mathrm{Mm} .90587, \mathrm{BC} 010685)^{-1832,-948}$ \\
\hline GCCTCCAAGGA & 37 & 22 & $101^{*}$ & 53 & $\begin{array}{l}\uparrow \text { glyceraldehyde-3-phosphate dehydrogenase (Mm. 5289, } \\
\text { AK081405)-1086/ }\end{array}$ \\
\hline TTGCTTTGTTG & 5 & 9 & 6 & $47^{*}$ & $\begin{array}{l}\uparrow \text { phosphoenolpyruvate carboxykinase } 1 \text {, cytosolic (Mm. } 42246 \text {, } \\
\text { BC037629) }\end{array}$ \\
\hline GGACAGCACAC & 1 & 9 & $73^{*}$ & 37 & $\uparrow$ pyruvate carboxylase $(\mathrm{Mm} .1845, \mathrm{M} 97957)^{-1894,-1843,-504 /}$ \\
\hline GCTTGTGACGA & 0 & 0 & 0 & $17^{\star}$ & $\uparrow$ transaldolase $1(\mathrm{Mm} .29182, \mathrm{BC} 04754)$ \\
\hline GGATGCTGGGT & 24 & 18 & 48 & $94^{*}$ & $\uparrow$ transketolase $\left(\mathrm{Mm} .154387\right.$, AK012794) ${ }^{/-1325,-1249}$ \\
\hline TAAGGGAAATA & 3 & 0 & 0 & $22^{*}$ & $\uparrow$ triosephosphate isomerase $(\mathrm{Mm} .4222, \mathrm{X53333})$ \\
\hline CCAAATAAAAC & 12 & 19 & $2^{*}$ & 49 & $\downarrow$ lactate dehydrogenase $1, \mathrm{~A}$ chain $(\mathrm{Mm} .141443, \mathrm{U13687})$ \\
\hline TTCCAGCTGCT & 59 & 63 & 23 & $9^{*}$ & $\begin{array}{l}\downarrow \text { phosphoglycerate mutase } 1(\mathrm{Mm} .16783 \text {, } \\
\mathrm{BC} 002241)^{-1121,-469 /-476}\end{array}$ \\
\hline \multicolumn{6}{|r|}{ (1) } \\
\hline TGCCTTCTCTG & 0 & 0 & 0 & $12^{*}$ & $\begin{array}{l}\uparrow \text { acyl-coenzyme A dehydrogenase, very long chain (Mm. 18630, } \\
\text { BC026559)-713/ }\end{array}$ \\
\hline GAACAGTCGAC & 15 & 13 & 12 & $99^{*}$ & $\begin{array}{l}\uparrow \text { adipocyte complement-related protein (Mm. 3969, } \\
\text { BC028770)-836/-865 }\end{array}$ \\
\hline CATCGCCAGTG & 118 & 90 & $398^{*}$ & 118 & $\uparrow$ apolipoprotein E (Mm. 156335, BC028816) \\
\hline TTTGCTTTAAA & 8 & 11 & 6 & $47^{*}$ & $\begin{array}{l}\uparrow \text { ATP citrate lyase; RIKEN (Mm. 25316, BC021502; Mm. 45765, } \\
\text { BC021413)-633,-391/-575 }\end{array}$ \\
\hline GAACATTTCAG & 1 & 0 & 6 & $31^{*}$ & $\uparrow$ EST ATP citrate lyase (Mm. 25316, BY687740)-633,-391/-575 \\
\hline TTGAGCTCTGA & 3 & 2 & 1 & $22^{*}$ & $\uparrow$ carboxylesterase $3(\mathrm{Mm} .120807, \mathrm{BC} 019198)^{\prime-345}$ \\
\hline CTGCATAGCTC & 3 & 1 & 1 & $19^{*}$ & $\uparrow$ CD36 antigen $(\mathrm{Mm} .18628$, AK052825) \\
\hline TATGTCCACGA & 0 & 1 & $15^{*}$ & 12 & $\uparrow$ diacylglycerol O-acyltransferase 1 (Mm. 22633, BC003717) \\
\hline TGGGTGTCCAG & 1 & 2 & 5 & $37^{*}$ & $\begin{array}{l}\uparrow \text { fatty acid coenzyme A ligase, long chain } 2 \text { (Mm. 28962, } \\
\text { AK004897) }\end{array}$ \\
\hline ATGCAGGGCCA & 43 & 66 & $520^{*}$ & 126 & $\uparrow$ fatty acid synthase (Mm. 3760, AF127033) \\
\hline ACTCAATTCAG & 22 & 26 & $131^{*}$ & 30 & $\begin{array}{l}\uparrow \text { glycerol-3-phosphate dehydrogenase } 1 \text { (soluble) (Mm. 10669, } \\
\text { BC019391)-156/ }\end{array}$ \\
\hline GCTTCCTGAGC & 3 & 0 & 10 & $16^{*}$ & $\uparrow$ hormone-sensitive lipase $(\mathrm{Mm} .1721, \mathrm{BC} 021642)^{/-516}$ \\
\hline GTCTAAAATTA & 8 & 3 & 4 & $29^{*}$ & $\uparrow$ lipoprotein lipase $(\mathrm{Mm} .1514$, AK002645) \\
\hline ACAAGTCTCTG & 0 & 1 & 1 & $37^{\star}$ & $\uparrow$ EST lipoprotein lipase (Mm. 1514, AA537700) \\
\hline CAAAGCCCCAC & 12 & 38 & $8^{*}$ & 24 & $\downarrow$ EST lipoprotein lipase (Mm. 1514, BE625478) \\
\hline TGTAACAAATG & 2 & 0 & 9 & $12^{*}$ & $\uparrow$ long chain fatty acyl elongase (Mm. 26171, AK029029) \\
\hline CTCAGTATCCC & 3 & 2 & $19^{*}$ & 6 & $\begin{array}{l}\uparrow \text { low-density lipoprotein receptor-related protein } 1 \text { (Mm. } 7221 \text {, } \\
\text { X67469) }\end{array}$ \\
\hline TTGTCAGGTAG & 4 & 14 & 2 & $54^{*}$ & $\begin{array}{l}\uparrow \text { malic enzyme, supernatant (Mm. 148155, } \\
\text { J02652) }\end{array}$ \\
\hline TGAGCATCGGG & 15 & 16 & $75^{\star}$ & 41 & $\uparrow$ monoglyceride lipase (Mm. 194795, AJ316580)-1068,-594/ \\
\hline GTCTGGGGGGA & 167 & 91 & 124 & $27^{*}$ & $\downarrow$ EST monoglyceride lipase (Mm. 194795, BE651758)-1068,-594/ \\
\hline GGCAAGTGCTA & 1 & 5 & 19 & $35^{\star}$ & $\uparrow$ stearoyl-coenzyme A desaturase 1 (Mm. 140785, AF509570) \\
\hline AAAACCATTGC & $29^{*}$ & 89 & 78 & $358^{*}$ & - stearoyl-coenzyme A desaturase 1 (Mm. 140785, BC007474) \\
\hline GCTGCCCTGGG & 1 & 0 & $18^{*}$ & 11 & $\uparrow$ EST stearoyl-coenzyme A desaturase 1 (Mm. 140785, AA415297) \\
\hline AGATAGATTTG & 12 & 4 & $30^{*}$ & 17 & $\begin{array}{l}\uparrow \text { sterol carrier protein 2, liver }(\mathrm{Mm} .1779 \\
\mathrm{BC} 034613)^{-1000 /-1479,-1136,-721,-656}\end{array}$ \\
\hline TGGATGCCTTC & 36 & 22 & 21 & $1^{*}$ & $\begin{array}{l}\downarrow \text { alcohol dehydrogenase } 1 \text {, class I (Mm. 2409, } \\
\text { BC013477) }\end{array}$ \\
\hline GACACCAGAGC & 4 & 12 & 1 & $0^{*}$ & $\downarrow$ brain acyl-CoA hydrolase (Mm. 197523, BC013507) \\
\hline AAGACCTATGT & 519 & 265 & $95^{*}$ & $65^{*}$ & $\downarrow$ diazepam binding inhibitor (Mm. 2785, BC028874) $)^{-1234 /}$ \\
\hline AGCCAAAGGAA & 276 & 380 & $73^{*}$ & 273 & $\begin{array}{l}\downarrow \text { fatty acid binding protein } 4 \text {, adipocyte (Mm. 582, } \\
\text { BC002148) }\end{array}$ \\
\hline
\end{tabular}

I, intact; G, GDX; 3 h, DHT3h; 24 h, DHT24h.

*Significantly different $(P<0.05)$ from G. Arrows are used to show a simplified representation of the effects of DHT. When castration induces a significant change in expression level, a dash is used instead of an arrow. 
Table 3 Differentially expressed transcripts involved in energy metabolism

\begin{tabular}{|c|c|c|c|c|c|}
\hline Tags & I & G & $3 \mathbf{h}$ & $24 \mathrm{~h}$ & Description (UniGene, Genbank) TGTTCT/AGAACA \\
\hline CAACTGTATTT & 1 & 1 & 2 & $20^{*}$ & $\uparrow$ aconitase 2, mitochondrial (Mm. 154581, BC004645) $)^{-390 /}$ \\
\hline CATCTTCAGCC & 20 & 13 & $49^{*}$ & 16 & $\begin{array}{l}\uparrow \text { ATPase, Ca++ transporting, cardiac muscle, fast twitch } 1 \\
(\mathrm{Mm} .35134, \text { AY081946) }\end{array}$ \\
\hline CGGGAGATGCT & 2 & 1 & 1 & $16^{*}$ & $\begin{array}{l}\uparrow \text { ATP synthase, } \mathrm{H}^{+} \text {transporting, mitochondrial F1 complex, } \\
\text { O subunit }(\mathrm{Mm} .41, \mathrm{BC} 012241)\end{array}$ \\
\hline CAGGCCACACA & 1 & 5 & 0 & $45^{\star}$ & $\begin{array}{l}\uparrow \text { ATP synthase, } \mathrm{H}+\text { transporting mitochondrial F1 complex, } \\
\beta \text { subunit }(\mathrm{Mm} .103838, \mathrm{AK} 010314)\end{array}$ \\
\hline ATAATACATAA & 190 & 139 & 102 & $346^{\star}$ & $\uparrow$ ATP synthase FO subunit $6(8593-8607)^{\star *}$ \\
\hline TAGATATAGGC & 99 & 116 & $28^{*}$ & $38^{*}$ & $\downarrow$ ATP synthase FO subunit 6 (8596-8582) \\
\hline TTGATGTATCT & 0 & 0 & 0 & $17^{*}$ & ATP synthase FO subunit 8 (7791-7777) \\
\hline AGGACAAATAT & 25 & 36 & $224^{*}$ & $138^{*}$ & $\uparrow$ cytochrome b (14539-14553) \\
\hline ITGTGTGG & 5 & 3 & 1 & $29^{*}$ & $\uparrow$ cytochrome c oxidase, subunit VIc (Mm. 548, BC024666) \\
\hline TATTGGCTCTG & 0 & 0 & 1 & $36^{*}$ & $\begin{array}{l}\uparrow \text { cytochrome c oxidase, subunit VIIla (Mm. 14022, } \\
\text { AK002218)-1524/-703,-641 }\end{array}$ \\
\hline AGGAGGACTTA & 2 & 7 & 17 & $48^{\star}$ & $\uparrow N A D H$ dehydrogenase subunit 2 (4410-4424) \\
\hline GCTGCCCTCCA & 732 & 568 & $131^{*}$ & 330 & $\downarrow$ cytochrome $c$ oxidase subunit 1 (6813-6827) \\
\hline TGGTGTAAGCA & 93 & 98 & $12^{*}$ & $4^{\star}$ & $\downarrow$ cytochrome $c$ oxidase subunit 1 (6676-6662) \\
\hline ATGAGAACAGC & 16 & 25 & $1^{*}$ & $1^{*}$ & cytochrome c oxidase subunit 1 (6731-6717) \\
\hline AAGTCATTCTA & 23 & 68 & $1^{*}$ & $7^{*}$ & $\downarrow$ cytochrome $c$ oxidase subunit 1 (6816-6802) \\
\hline GGCAGTTACGA & 1 & 7 & $45^{*}$ & 17 & $\uparrow$ cytochrome c oxidase subunit 1 (5511-5497) \\
\hline TAGTTACTTAC & 9 & 19 & 13 & $127^{*}$ & $\begin{array}{l}\uparrow \text { cytochrome c oxidase subunit } 1 \text { (6093-6107); NEW1 domain } \\
\text { containing protein (Mm. 22338, AK046719) }\end{array}$ \\
\hline AGCAGTCCCCT & 625 & 550 & 336 & $82^{*}$ & $\downarrow$ cytochrome $c$ oxidase subunit 2 (7497-7511) \\
\hline AGTGGAGGACG & 132 & 91 & 40 & $26^{*}$ & $\downarrow$ cytochrome $c$ oxidase subunit $2(7500-7486)$ \\
\hline CTGCGGCTTCA & 42 & 41 & $6^{*}$ & $5^{\star}$ & cytochrome c oxidase subunit 3 (9325-9311) \\
\hline AGCAATTCAAA & 7 & 24 & $2^{*}$ & 27 & $\downarrow N A D H$ dehydrogenase subunit 3 (9682-9696) \\
\hline GTAGTGGAAGT & 45 & 110 & $9^{*}$ & $26^{*}$ & $\downarrow$ NADH dehydrogenase subunit 3 (9685-9671) \\
\hline ATGACTGATAG & $259^{*}$ & 696 & $179^{*}$ & $162^{*}$ & - NADH dehydrogenase subunit $4(11230-11244)$ \\
\hline GAGTTTGGATT & 12 & 25 & 5 & $4^{\star}$ & $\downarrow N A D H$ dehydrogenase subunit 4 (11080-11066) \\
\hline ATTATAGTACG & 9 & 19 & 3 & $0^{*}$ & $\downarrow N A D H$ dehydrogenase subunit 4 (11192-11178) \\
\hline GTTTTGGATTA & 2 & 2 & 15 & $44^{*}$ & $\uparrow \mathrm{NADH}$ dehydrogenase subunit 4 (10671-10657) \\
\hline
\end{tabular}

I, intact; G, GDX; 3 h, DHT3h; 24 h, DHT24h.

*Significantly different $(P<0.05)$ from $\mathrm{G}$. Arrows are used to show a simplified representation of the effects of DHT. When castration induces a significant change in expression level, a dash is used instead of an arrow.

${ }^{*}$ Tags matching the mitochondrial genome (Genbank accession no. NC_001569); values listed for these tags indicate the locus within the mitochondrial genome.

by DHT, 69 transcripts downregulated by DHT and 10 transcripts regulated by castration.

Genes involved in the glycolysis pathway, such as the aldolase 1 A isoform, enolase 1 alpha nonneuron and glyceraldehyde-3-phosphate dehydrogenase (Table 2), as well as transcripts implicated in de novo fatty acid synthesis, such as ATP citrate lyase and fatty acid synthase, were upregulated by DHT (Table 2). Furthermore, two transcripts of the triacylglycerol synthesis pathway, namely, glycerol-3phosphate dehydrogenase 1 (soluble) (GPD1) and diacylglycerol $O$-acyltransferase (DGAT) 1, were upregulated (Table 2). Genes involved in lipolysis, such as hormone-sensitive lipase, were also upregulated by DHT. Apolipoprotein E and low-density lipoprotein receptor-related protein 1 gene expression was increased by DHT, whereas a switch of transcript species of lipoprotein lipase (LPL) and monoglyceride lipase was observed (Table 2).

Transcripts implicated in energy metabolism (Table 3) as well as in amino-acid metabolism, nucleotide metabolism, transport metabolism, protein modification and general metabolism (Table 4), displayed numerous patterns of gene expression after androgen modulation. Cell division was also affected, since almost all the differentially expressed genes related to cell cycle, including cyclin I, and the genes associated with apoptosis, such as fat-specific gene 27, were upregulated by DHT (Table 5). 
Table 4 Differentially expressed transcripts involved in other metabolism

\begin{tabular}{|c|c|c|c|c|c|}
\hline Tags & I & G & $3 \mathrm{~h}$ & $24 \mathrm{~h}$ & Description (UniGene, Genbank) TGTTCT/AGAACA \\
\hline Amino acid & & & & & \\
\hline GAAACTCTACT & 7 & 3 & 21 & $36^{*}$ & $\begin{array}{l}\uparrow \text { cysteine dioxygenase } 1 \text {, cytosolic (Mm. 29996, } \\
\mathrm{BC} 013638)^{-1838 /-1884}\end{array}$ \\
\hline TATAGTATGTT & 1 & 0 & 0 & $35^{*}$ & $\begin{array}{l}\uparrow \text { glutamate-ammonia ligase (glutamine synthase) (Mm. } 2338 \text {, } \\
\text { AY044241) }\end{array}$ \\
\hline Nucleotide & & & & & \\
\hline TCCTTGGGGGT & 18 & 2 & $19^{*}$ & 7 & $\begin{array}{l}\uparrow \text { histidine triad nucleotide binding protein (Mm. 425, } \\
\text { AK012433)-1300,-358/-1311,-384 }\end{array}$ \\
\hline GTGCTGCCAGT & 17 & 45 & $8^{*}$ & $1^{*}$ & $\begin{array}{l}\downarrow \text { ectonucleotide pyrophosphatase/phosphodiesterase } 2 \\
(\mathrm{Mm} .28107, \mathrm{AF} 123542)^{\prime-1508}\end{array}$ \\
\hline Transport & & & & & \\
\hline GTCAATGACGT & 3 & 0 & $15^{*}$ & 7 & $\uparrow$ aquaporin $1(\mathrm{Mm} .18265, \mathrm{BC} 007125)$ \\
\hline TCAGGCTGCCT & 15 & 11 & 4 & $72^{*}$ & $\uparrow$ ferritin heavy chain (Mm. 1776, BC012314)-1572,-599/-1289,-546 \\
\hline CCCTGGGTTCT & 10 & 24 & $149^{*}$ & 58 & $\begin{array}{l}\uparrow \text { ferritin light chain 1; ESTs similar to ferritin L subunit 2; } \\
\text { EST RIKEN (Mm. 7500, BC019840; Mm. 220829, BQ950380; } \\
\text { Mm. 34374, BI789635) }\end{array}$ \\
\hline СТTСТСАТTTG & 2 & 1 & 3 & $18^{*}$ & $\begin{array}{l}\uparrow \text { lyosomal-associated protein transmembrane 4A (Mm. 30071, } \\
\text { AK084515)-1464/-1610 }\end{array}$ \\
\hline ААТTТСТTССТ & 0 & 0 & 0 & $93^{*}$ & $\begin{array}{l}\uparrow \text { major urinary protein } 1 \text { and } 2 \text { (Mm. 157893, BC012221; } \\
\text { Mm. 4516, BC012259) }\end{array}$ \\
\hline CAGAAGAAGCT & 0 & 0 & 0 & $29^{*}$ & $\uparrow$ EST major urinary protein 1 (Mm. 157893, CA457333) \\
\hline AGTCTCGAGGG & 1 & 5 & 1 & $38^{*}$ & $\uparrow$ solute carrier family 1, member $7(\mathrm{Mm} .1056, \mathrm{BC} 037462)^{/-1252}$ \\
\hline GTCAGGTCACA & 3 & 1 & $15^{*}$ & $16^{*}$ & $\begin{array}{l}\uparrow \text { solute carrier family } 25 \text { (mitochondrial carrirer; citrate transporter), } \\
\text { member } 1(\mathrm{Mm} .229291, \mathrm{BC} 037087)\end{array}$ \\
\hline Protein modificati & & & & & \\
\hline CAGGTGTCCAC & $14^{*}$ & 0 & 3 & 1 & $\begin{array}{l}\text { - EST protein tyrosine phosphatase 4a2; EST RIKEN } \\
(\mathrm{Mm} .193688, \text { AV049645; Mm. 36280, AU024264) }\end{array}$ \\
\hline $\begin{array}{l}\text { General } \\
\text { TGGAGATAAGC }\end{array}$ & 2 & 3 & $26^{*}$ & $23^{*}$ & $\begin{array}{l}\uparrow \text { acid phosphatase 5, tartrate resistant (Mm. } 46354 \text {, } \\
\text { BC019160) }\end{array}$ \\
\hline
\end{tabular}

I, intact; G, GDX; 3 h, DHT3h; 24 h, DHT24h.

*Significantly different $(P<0.05)$ from G. Arrows are used to show a simplified representation of the effects of DHT. When castration induces a significant change in expression level, a dash is used instead of an arrow.

Some transcripts involved in RNA synthesis function displayed downregulation, except for the $\mathrm{DEAD} / \mathrm{H}$ (Asp-Glu-Ala-Asp/His) box polypeptide 5 and the CGAAT/enhancer binding protein $(\mathrm{C} / \mathrm{EBP})$ alpha transcripts, which were upregulated by DHT (Table 5). Genes associated with cell signaling, such as resistin and growth hormone receptor, were upregulated by DHT, whereas others, such as calmodulin 4, were downregulated (Table 5). Keratins (K), which are implicated in the cytoskeleton, were all downregulated by DHT (Table 6). On the other hand, other cytoskeletal components, such as actin beta cytoplasmic and gelsolin, as well as transcripts related to extracellular matrix, such as various procollagen isoforms, secreted acidic cysteine-rich glycoprotein (SPARG) and matrix metalloproteinase 2 (MMP-2), were upregulated by DHT (Table 6). Genes involved in cell and organism defense, such as superoxide dismutase 3 extracellular, glutathione peroxidases 3 and 4 , and transcripts of the histocompatibility 2 complex, were upregulated by DHT (Table 7). In contrast, other transcripts, such as carbonic anhydrases, heat-shock proteins 1 and 4, adipsin (EST) and lysozyme, were downregulated. Finally, transcripts associated with protein synthesis were affected in different ways by the androgen (Table 8). In addition, many novel transcripts were significantly differentially expressed (Table 9). Remarkably, $24 \mathrm{~h}$ after DHT injection, the tag CATG TTTGACAATGA was increased 353 times, whereas the tag CATG TCGGTATAAGG was decreased by almost 300-fold. 
Table 5 Differentially expressed transcripts involved in cell division, RNA synthesis and cell signalling

\begin{tabular}{|c|c|c|c|c|c|}
\hline Tags & I & G & $3 \mathrm{~h}$ & $24 \mathrm{~h}$ & Description (UniGene, Genbank) TGTTCT/AGAACA \\
\hline \multicolumn{6}{|l|}{ Cell cycle } \\
\hline TACTGCTGATA & 0 & 0 & 0 & $13^{*}$ & $\uparrow$ cyclin I (Mm. 22711, BC003290)/-507 \\
\hline CTGTTTCAAGG & 12 & 4 & $34^{*}$ & 12 & $\uparrow$ G0/G1 switch gene $2(\mathrm{Mm} .3283$, AK003165)-645/-1831,-595 \\
\hline GCGGCGGATGG & 88 & 40 & $257^{*}$ & 72 & $\uparrow$ lectin, galactose binding, soluble 1 (Mm. 43831, NM_008495) \\
\hline \multicolumn{6}{|l|}{ Apoptosis } \\
\hline GCTTATAGATC & 2 & 2 & $19^{*}$ & 1 & $\uparrow$ B-cell receptor-associated protein 31 (Mm. 17, BC002106) \\
\hline CAGCTGCCTCT & 4 & 0 & 3 & $76^{\star}$ & $\uparrow$ fat specific gene $27(\mathrm{Mm} .10026, \text { AK080133) })^{-575 /-300}$ \\
\hline TGGGTTGTCTA & 34 & 60 & $12^{*}$ & 76 & $\downarrow$ tumor protein, translationally-controlled 1 (Mm. 254, X06407)/-595 \\
\hline \multicolumn{6}{|c|}{ Chromosome structure } \\
\hline TCGATGTCTGA & $23^{*}$ & 0 & 0 & 0 & - protamine 2 (Mm. 541, AK005729) \\
\hline \multicolumn{6}{|r|}{ (70) } \\
\hline TCAACAAGCAC & 3 & 15 & $0^{*}$ & 10 & $\downarrow$ EST synaptonemal complex protein 3 (Mm. 148209, AW490250) \\
\hline \multicolumn{6}{|l|}{ RNA processing } \\
\hline GCCTTCCAATA & 1 & 0 & 1 & $12^{*}$ & $\begin{array}{l}\uparrow \text { DEAD/H (Asp-Glu-Ala-Asp/His) box polypeptide } 5 \text { (Mm. 19101, } \\
\text { BC009142) }\end{array}$ \\
\hline GGCAGCACAAA & 15 & 12 & 9 & $0^{*}$ & $\begin{array}{l}\downarrow \text { EST heterogeneous nuclear ribonucleoprotein L (Mm. 9043, } \\
\text { BB399813)-1466/ }\end{array}$ \\
\hline \multicolumn{6}{|c|}{ Transcription factors } \\
\hline CTAGATGTCGT & 0 & 1 & 1 & $17^{\star}$ & $\uparrow \mathrm{C} / \mathrm{EBP} \alpha(\mathrm{Mm} .34537, \mathrm{BC} 011118)$ \\
\hline ACGCAGTGGGT & 9 & 14 & 7 & $0^{*}$ & $\downarrow$ EST nuclear factor I/A (Mm. 4771, AK004196) \\
\hline \multicolumn{6}{|l|}{ General } \\
\hline CACGTGCCTGA & 38 & 21 & 10 & $1^{*}$ & $\downarrow$ zinc-finger homeobox 1b (Mm. 37676, AF033116) \\
\hline \multicolumn{6}{|l|}{ Cell adhesion } \\
\hline TGAGCTTTGGG & 9 & 0 & $26^{*}$ & 8 & $\begin{array}{l}\text { melanoma cell adhesion molecule (Mm. 39103, } \\
\mathrm{BC} \text { (M6985) }\end{array}$ \\
\hline CAATGTGGGTT & 0 & 0 & 0 & $20^{*}$ & 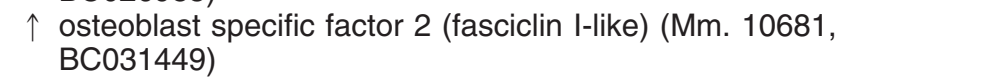 \\
\hline TGCAGGTGCAC & 22 & 21 & 19 & $3^{*}$ & $\begin{array}{l}\downarrow \text { EST integrin } \beta 1 \text { (fibronectin receptor } \beta)(\mathrm{Mm} .4712 \text {, } \\
\text { BB109045) }\end{array}$ \\
\hline \multicolumn{6}{|l|}{ Effector modulator } \\
\hline ACTCGGAGCCA & 60 & 42 & 21 & $7^{*}$ & $\downarrow$ calmodulin 1 (Mm. 34246, AK004673)-1928/-1360,-965 \\
\hline AGTGAGGAAGA & 14 & 15 & 0 * & $1^{*}$ & $\downarrow$ calmodulin $4(\mathrm{Mm} .21075$, AK009664) \\
\hline TTTTTGAACAA & 26 & 34 & 13 & $3^{*}$ & $\downarrow$ catenin beta (Mm. 3476, BC006739) \\
\hline TGCACACAACT & 24 & 29 & $1^{*}$ & $0^{*}$ & $\begin{array}{l}\downarrow \text { S100 Ca binding protein A3 (Mm. 703, } \\
\text { AF004941) }\end{array}$ \\
\hline TATCCCACGCC & 1 & 3 & 0 & $24^{*}$ & $\begin{array}{l}\uparrow \mathrm{S} 100 \mathrm{Ca} \text { binding protein A11 (calizzarin) (Mm. 175848, } \\
\mathrm{BC} 021916)^{-1504,-872 /-1869}\end{array}$ \\
\hline \multicolumn{6}{|c|}{ Hormone/growth factors } \\
\hline CCACTGTGTCC & 9 & 7 & $70^{*}$ & 26 & $\uparrow$ resistin (Mm. 1181, AF290870)-1877/ \\
\hline \multicolumn{6}{|l|}{ Receptors } \\
\hline CATACGCATAA & 3 & 0 & 0 & $18^{*}$ & $\begin{array}{l}\uparrow \text { growth hormone receptor }(\mathrm{Mm} .3986, \\
\mathrm{BC} 024375)^{-411,-366,-292,-231,-222 /-1064}\end{array}$ \\
\hline GTCTGCTGATG & $77^{*}$ & 23 & 53 & 23 & $\begin{array}{l}\text { - guanine nucleotide binding protein, beta } 2 \text {, related sequence } 1 \\
\text { (Mm. 5305, X75313) }\end{array}$ \\
\hline GAATATGCAGC & 4 & 19 & $0^{*}$ & $0^{*}$ & $\downarrow$ kinase insert domain protein receptor (Mm. 285, AK031739)/-1554 \\
\hline CAAACTTTATA & $8^{*}$ & 37 & $5^{\star}$ & $2^{*}$ & — pheromone receptor V3R4 (Mm. 160379, AF324869) $)^{-1599,-1094 /}$ \\
\hline
\end{tabular}

I, intact; G, GDX; 3 h, DHT3h; 24 h, DHT24h.

*Significantly different $(P<0.05)$ from G. Arrows are used to show a simplified representation of the effects of DHT. When castration induces a significant change in expression level, a dash is used instead of an arrow. 
Table 6 Differentially expressed transcripts involved in cytoskeletal and extracellular matrix

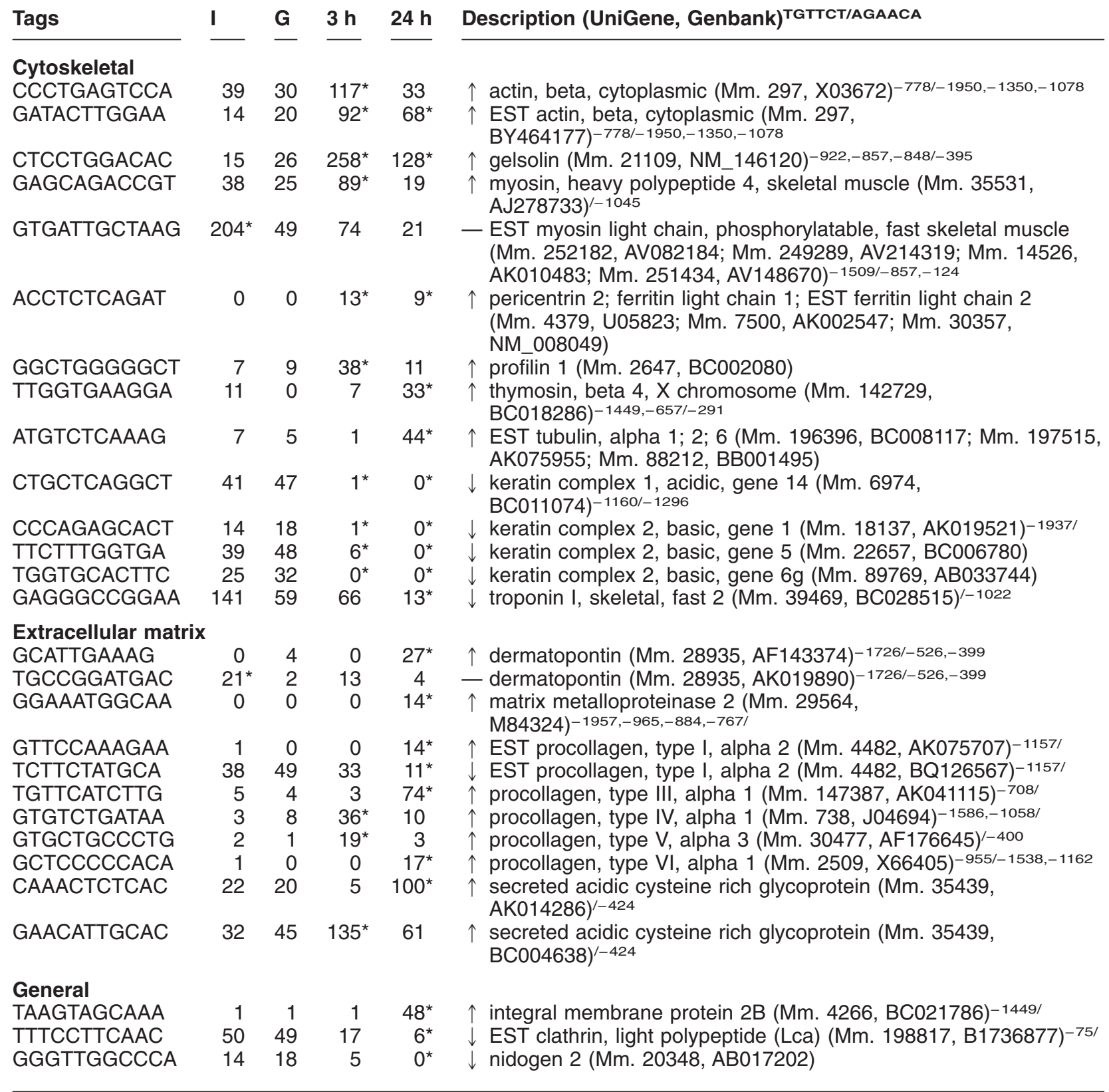

I, intact; G, GDX; 3 h, DHT3h; 24 h, DHT24h.

*Significantly different $(P<0.05)$ from G. Arrows are used to show a simplified representation of the effects of DHT. When castration induces a significant change in expression level, a dash is used instead of an arrow.

Among the 176 differentially expressed transcripts presented in Tables 2-8, excluding the transcripts from mitochondrial genome, 118 possessed one or more potential HRE in there promoter sequence. Moreover, 29 of these transcripts had one or more potential HRE $500 \mathrm{bp}$ upstream of the transcription initiation start. 
Table 7 Differentially expressed transcripts involved in general homeostasis, stress response and immunity

\begin{tabular}{|c|c|c|c|c|c|}
\hline Tags & I & G & $3 \mathbf{h}$ & $24 \mathrm{~h}$ & Description (UniGene, Genbank) TGTTCT/AGAACA \\
\hline \multicolumn{6}{|l|}{ General } \\
\hline CCCTGCCTTAA & 0 & 2 & 4 & $19^{*}$ & $\uparrow$ creatine kinase, muscle (Mm. 2375, AK009950)/-745 \\
\hline GAAAAGTGGAT & 2 & 0 & $16^{*}$ & 6 & $\uparrow$ epoxide hydrolase 2 , cytoplasmic (Mm. 15295, BC015087)-936/ \\
\hline СТATCСTCTCA & 22 & 19 & 12 & $93^{*}$ & $\uparrow$ glutathione peroxidase $3(\mathrm{Mm} .7156$, AK002219)-229/-1647 \\
\hline AAGGTCTGCCT & 13 & 19 & $98^{*}$ & 33 & $\uparrow$ glutathione peroxidase 4 (Mm. 2400, D87896) \\
\hline GAAGAGGGGGA & $74^{*}$ & 15 & 28 & $71^{*}$ & - haptoglobin (Mm. 26730, M96827)-1792,-1191/-820,-545 \\
\hline GGGGGAGTGGA & 2 & 0 & $24^{*}$ & 4 & $\uparrow$ neuronatin $(\mathrm{Mm} .140956, \mathrm{BC} 036984)^{/-151}$ \\
\hline TTTCCAGGTGT & 0 & 0 & 2 & $24^{*}$ & $\uparrow$ selenoprotein W, muscle 1 (Mm. 42829, NM_009156) \\
\hline TATCTGTGCAT & 29 & 65 & $14^{*}$ & $13^{*}$ & $\downarrow$ selnoprotein P, plasma, $1(\mathrm{Mm} .22699, \mathrm{X} 99807)^{/-556}$ \\
\hline TTCCCGATCAC & 8 & 4 & $34^{*}$ & 10 & $\uparrow \begin{array}{l}\text { superoxide dismutase } 3 \text {, extracellular (Mm. 2407, } \\
\text { BC010975) }\end{array}$ \\
\hline CTACGTTCTCT & 1 & 0 & 0 & $12^{*}$ & $\uparrow$ thioredoxin-like $2(\mathrm{Mm} .29675$, AK010354)-846,-313/-1003 \\
\hline CCCTGAGGGGT & 89 & 51 & $279^{*}$ & 79 & $\uparrow$ transferrin (Mm. 37214, BC012313) $)^{-1703,-673 /-1061}$ \\
\hline AGCAAGATGGT & 21 & 46 & $12^{*}$ & $2^{*}$ & $\downarrow$ aminolevulinic acid synthase $1(\mathrm{Mm} .19143, \mathrm{BC} 022110)^{-1396 /}$ \\
\hline CCTATTAAAAA & 987 & 1185 & 813 & $239^{*}$ & carbonic anhydrase $3(\mathrm{Mm} .300, \mathrm{BC} 011129)$ \\
\hline AАTTTCACACC & $90^{*}$ & 232 & 142 & 451 & - carbonic anhydrase $3(\mathrm{Mm} .300, \mathrm{M} 27796)$ \\
\hline GGTGTGTTTTA & 28 & 53 & 23 & $15^{\star}$ & $\downarrow$ EST carbonic anhydrase 3 (Mm. 300, AV291195) \\
\hline GGAGGCAGAGG & 10 & 16 & 10 & $1^{*}$ & $\begin{array}{l}\downarrow \text { carbonic anhydrase 5a, mitochondrial (Mm. 116761, } \\
\text { BC030174) }\end{array}$ \\
\hline TGAACCGTCCC & 33 & 27 & $4^{*}$ & 8 & $\downarrow$ glutathione S-transferase, pi 2 (Mm. 426, BC002048)-1262,-1185/ \\
\hline \multicolumn{6}{|l|}{ Stress response } \\
\hline TATTAGTCTTA & 30 & 27 & 13 & $5^{\star}$ & $\downarrow$ heat-shock protein, 1 (Mm. 1843, AK004658) \\
\hline CTGAGCAGAAT & 10 & 25 & $4^{*}$ & $1^{*}$ & $\begin{array}{l}\downarrow \text { heat-shock protein } 4(\mathrm{Mm} .1032 \text {, } \\
\text { BC003770)-1383,-996/-1768,-1341 }\end{array}$ \\
\hline GAATAATAAAA & 3 & 1 & 2 & $18^{*}$ & $\begin{array}{l}\uparrow \text { heat-shock protein 8; EST heat shock cognate hsc 73; } \\
\text { ESTs (Mm. 197551, BC006722; Mm. 258783, BY761643; } \\
\text { Mm. 247242, BY415840) }\end{array}$ \\
\hline \multicolumn{6}{|l|}{ Immunity } \\
\hline GAGTGGATTCT & 1 & 0 & 0 & $14^{*}$ & $\uparrow$ Cd63 antigen (Mm. 4426, BC012212) \\
\hline GTTGTTTTCCA & 2 & 0 & 0 & $12^{*}$ & 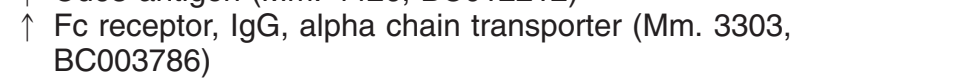 \\
\hline GATTGAGAATG & 11 & 14 & 5 & $55^{\star}$ & $\begin{array}{l}\uparrow \text { EST histocompatibility 2, D region locus I; L region; } \\
\text { histocompatibility 2, K region (Mm. 33263, AW 741231; } \\
\text { Mm. 196214, BY576457; Mm. 16771, BC011306) }\end{array}$ \\
\hline TCACACATTGC & 0 & 0 & $14^{*}$ & 4 & $\begin{array}{l}\uparrow \text { histocompatibility 2, Q region locus } 10 \text { (Mm. 88795, } \\
\text { K00614) }\end{array}$ \\
\hline GTTCAAGTGAC & 5 & 5 & 1 & $50^{\star}$ & $\uparrow$ la-associated invariant chain (Mm. 258212, BC003476) $)^{-1765 /}$ \\
\hline CTAATATTTGC & 0 & 0 & 0 & $12^{*}$ & $\begin{array}{l}\uparrow \text { immunoglobulin kappa chain, variable 8; 28; constant region; } \\
\text { EST RIKEN (Mm. 104747, BC028925; Mm. 220176, BC021781; } \\
\text { Mm. 222734, X02816; Mm. 255225, AK008450) }\end{array}$ \\
\hline GAGGACTGCCA & 28 & 16 & $57^{*}$ & 14 & $\uparrow$ lymphocyte antigen 6 complex, locus E (Mm. 788, BC019113) \\
\hline CATCTGAAAAA & 215 & 411 & $75^{\star}$ & 704 & $\downarrow$ EST adipsin (Mm. 4407, AW215391) \\
\hline TGTCAGTCTGT & 122 & 83 & 92 & $26^{*}$ & $\downarrow$ lysozyme $(\mathrm{Mm} .45436, \mathrm{BC} 002069)^{-581 /}$ \\
\hline
\end{tabular}

I, intact; G, GDX; 3 h, DHT3h; 24 h, DHT24h.

*Significantly different $(P<0.05)$ from G. Arrows are used to show a simplified representation of the effects of DHT. When castration induces a significant change in expression level, a dash is used instead of an arrow.

\section{Discussion}

There is much evidence that sex hormones mediate changes in adipose tissue distribution, the main observations indicating that there is a negative correlation between circulating testosterone levels and intra-abdominal fat mass and increased prognostic factors for atherosclerosis, risk of cardiovascular disease and diabetes (Seidell et al. 1990, Zumoff et al. 1990, Tsai et al. 2000). Through 
Table 8 Differentially expressed transcripts involved in protein synthesis

\begin{tabular}{|c|c|c|c|c|c|}
\hline Tags & $\mathbf{I}$ & $\mathbf{G}$ & $3 \mathrm{~h}$ & $24 \mathrm{~h}$ & Description (UniGene, Genbank) TGTTCT/AGAACA \\
\hline & & & & & \\
\hline TGAACACTGAA & 1 & 1 & 1 & $18^{*}$ & $\begin{array}{l}\uparrow \text { transglutaminase 2, C polypeptide (Mm. 18843, } \\
\text { BC016492) }\end{array}$ \\
\hline TAGCTTCCTCT & 0 & 0 & 1 & $12^{*}$ & $\begin{array}{l}\uparrow \text { sequestosome 1; EST RIKEN (Mm. 200125, BC006019; } \\
\text { Mm. 41784, BM207023) }\end{array}$ \\
\hline Protein turnover & & & & & \\
\hline & 29 & 27 & $110^{*}$ & 43 & $\begin{array}{l}\uparrow \text { ubiquitin C; EST RIKEN (Mm. 331, BC021837; Mm. 41423, } \\
\text { BB476893)-513/ }\end{array}$ \\
\hline GTAAGCATAAA & 1 & 2 & 0 & $19^{*}$ & $\uparrow$ EST ubiquitin B (Mm. 235, BU529368) \\
\hline TGACCCCGGGA & 1 & 2 & 1 & $24^{*}$ & $\begin{array}{l}\uparrow \text { ubiquitin A-52 residue ribosomal protein fusion product } 1 \\
(\mathrm{Mm} .43005, \mathrm{BC} 014772)\end{array}$ \\
\hline GTGGAGGCGCC & 99 & 88 & $2^{*}$ & $3^{\star}$ & $\downarrow$ cystatin E/M (Mm. 36816, NM_028623)-782/-1417,-1261 \\
\hline GAGTAAGGACA & 9 & 12 & $0^{*}$ & 1 & $\begin{array}{l}\downarrow \text { kallikrein } 7 \text { (chymotryptic, stratum coneum) (Mm. 34974, } \\
\text { BC027823) }\end{array}$ \\
\hline Translation factor & & & & & \\
\hline GAGCTCCAGCG & 18 & 3 & $35^{*}$ & 4 & $\begin{array}{l}\uparrow \begin{array}{l}\text { eukaryotic translation initiation factor 4E binding protein } 1 \\
(\mathrm{Mm} .6700, \mathrm{BC} 002045)^{-1790,-846 /-1808,-920,-816}\end{array}\end{array}$ \\
\hline TGCAATATGGC & 22 & 30 & 7 & $2^{*}$ & $\begin{array}{l}\downarrow \text { EST eukaryotic translation initiation factor } 4 \text { A2 (Mm. 16323, } \\
\text { BY674584) }\end{array}$ \\
\hline Ribosomal proteir & & & & & \\
\hline GGATTTGGCTT & 11 & 8 & 2 & $44^{*}$ & $\uparrow$ ribosomal protein, large P2 (Mm. 14245, BC012413)-859/-463 \\
\hline AACAATTTGGG & 3 & 1 & 0 & $37^{*}$ & $\uparrow$ ribosomal protein L9 (Mm. 14244, BC013165) \\
\hline TGGTCAGGATC & 17 & 12 & 2 & $0^{*}$ & $\downarrow$ EST ribosomal protein L9 (Mm. 14244, AV290443) \\
\hline ACATCATAGAT & 0 & 0 & 0 & $16^{*}$ & $\uparrow$ ribosomal protein L12 (Mm. 70127, BC018321)-1781/-1911 \\
\hline TGGATCAGTCT & 3 & 2 & 2 & $50^{*}$ & $\uparrow$ ribosomal protein L19 $(\mathrm{Mm} .30806, \mathrm{BC} 010710)^{-1598,-374 /-1653}$ \\
\hline CCAGAACAGAC & 8 & 5 & 1 & $32^{*}$ & $\uparrow$ ribosomal protein L30 (Mm. 3487, BC002060)-1200,-93/-204 \\
\hline GTGAAACTAAA & 5 & 4 & 2 & $32^{*}$ & 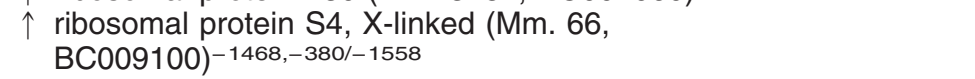 \\
\hline GACCTGGAGCC & 33 & 13 & $83^{*}$ & 24 & $\uparrow$ EST ribosomal protein S14 (Mm. 43778, AV094184)-1809,-221/ \\
\hline & 3 & 1 & 0 & $28^{*}$ & $\uparrow$ ribosomal protein S17 (Mm. 42767, BC002044) \\
\hline CTGTAGGTGAT & 0 & 0 & 1 & $23^{*}$ & $\uparrow$ ribosomal protein S23 (Mm. 30011, BC002145) \\
\hline TAAAGAGGCCG & 3 & 0 & 0 & $28^{*}$ & $\uparrow$ ribosomal protein S26 (Mm. 372, BC036987) $)^{1-374}$ \\
\hline GGCTTCGGTCT & 16 & 3 & 1 & $45^{\star}$ & $\begin{array}{l}\downarrow \text { ribosomal protein, large, P1; EST RIKEN (Mm. 3158, AK010656; } \\
\mathrm{Mm} .233844, \text { Al529467) }\end{array}$ \\
\hline GTTGCTGAGAA & 227 & 145 & 75 & $29^{*}$ & $\downarrow$ ribosomal protein $10(\mathrm{Mm} .100113, \mathrm{BC} 024901)^{--939,-660}$ \\
\hline & 172 & 145 & $32^{*}$ & $18^{*}$ & $\downarrow$ ribosomal protein L3 (Mm. 3486, BC009655)-1476/-1678.-1352,-1158 \\
\hline CTGCTATCCGA & 141 & 112 & 61 & $10^{*}$ & $\downarrow$ ribosomal protein L5 (Mm. 4419, BC026934) $)^{-1900,-1022 /}$ \\
\hline AATCCTGTGGA & 68 & 44 & 46 & $9^{*}$ & $\downarrow$ ribosomal protein L8 (Mm. 30066, U67771)-1256,-704,-628/ \\
\hline CCCACAAGGTA & 86 & 67 & 30 & $14^{*}$ & $\downarrow$ ribosomal protein L27 (Mm. 28985, BC024366) ${ }^{-244}$ \\
\hline ATCCGAAAGAA & 28 & 45 & 40 & $9^{*}$ & $\downarrow$ ribosomal protein L28 (Mm. 3111, BC024395) \\
\hline AAAACAGTGGC & 80 & 75 & 68 & $20^{\star}$ & $\downarrow$ ribosomal protein L37a (Mm. 21529, NM_009084) \\
\hline GGGAAGGCGGC & 170 & 88 & 58 & $23^{*}$ & $\downarrow$ ribosomal protein S3a (Mm. 6957, BC039659)-1876/ \\
\hline TATGTCAAGCT & 211 & 100 & 84 & $25^{\star}$ & $\downarrow$ ribosomal protein S12 (Mm. 21289, BC018362) \\
\hline CCTACCAAGAC & 171 & 118 & 68 & $28^{*}$ & $\downarrow$ ribosomal protein S20 $(\mathrm{Mm} .21938, \mathrm{BC} 011323)^{-1469,-1419,-1160}$ \\
\hline GCCTTTATGAG & 143 & 105 & 58 & $23^{*}$ & $\downarrow$ ribosomal protein S24 (Mm. 16775, AK002986) $)^{-589 /}$ \\
\hline GATGACACCAG & 138 & 66 & 81 & $13^{*}$ & $\downarrow$ ribosomal protein S28 (Mm. 200920, BC010987) $)^{-1690,-1556,-1375}$ \\
\hline CTAGTCTTTGT & 13 & 22 & $2^{*}$ & 42 & $\downarrow$ ribosomal protein S29 (Mm. 154915, BC024393) \\
\hline TTCAGCCCGTA & 13 & 16 & 31 & $1^{*}$ & $\downarrow$ EST ribosomal protein S29 (Mm. 154915, CA787284)-1560/ \\
\hline
\end{tabular}

I, intact; G, GDX; 3 h, DHT3h; 24 h, DHT24h.

*Significantly different $(P<0.05)$ from $\mathrm{G}$. Arrows are used to show a simplified representation of the effects of DHT. 
Table 9 Novel transcripts differentially expressed

\begin{tabular}{|c|c|c|c|c|c|c|c|c|c|c|}
\hline Tags & I & G & $3 \mathrm{~h}$ & $24 \mathrm{~h}$ & & Tags & $\mathbf{I}$ & G & $3 \mathrm{~h}$ & $24 \mathrm{~h}$ \\
\hline ATTTTCAGTTT & $7^{*}$ & 136 & $7^{*}$ & 115 & - & ATCTCACCCAG & 21 & 49 & $6^{*}$ & $10^{\star}$ \\
\hline TCCTACAGTGG & $2^{*}$ & 20 & $2^{*}$ & 7 & - & TCCACGTACAT & 9 & 18 & $2^{*}$ & $0^{\star}$ \\
\hline GAAAACGAGAA & $0^{\star}$ & 13 & 2 & 5 & - & GTGCAGGGGTG & 15 & 23 & $4^{*}$ & $2^{*}$ \\
\hline TTTGACAATGA & 0 & 1 & $85^{*}$ & $353^{*}$ & $\uparrow$ & GCTCTAGCTGC & 4 & 18 & $0^{*}$ & $1^{*}$ \\
\hline TTATAGACGGC & 1 & 11 & $58^{*}$ & $74^{\star}$ & $\uparrow$ & AGTCAGATTTC & 7 & 14 & $0^{*}$ & $0^{*}$ \\
\hline GTCACCTTTCG & 0 & 0 & $31^{*}$ & $47^{*}$ & $\uparrow$ & ACAGCAAGGGT & 5 & 14 & $0^{*}$ & $0^{\star}$ \\
\hline GGCTGCGGCCT & 3 & 7 & $288^{*}$ & $166^{*}$ & $\uparrow$ & GATGGAGACGG & 5 & 22 & $3^{*}$ & $3^{\star}$ \\
\hline CTTCCCCGGGA & 0 & 7 & $47^{\star}$ & 26 & $\uparrow$ & ATAGACTTTCA & 8 & 12 & $0^{*}$ & $0^{*}$ \\
\hline GCCTCCTGGGT & 2 & 0 & $40^{*}$ & $18^{*}$ & $\uparrow$ & ATCTCGAGAGG & 5 & 15 & $1^{*}$ & 2 \\
\hline GATGGAGTGAC & 1 & 1 & $25^{\star}$ & 3 & $\uparrow$ & TCCCCGTACAA & 36 & 42 & 16 & $0^{\star}$ \\
\hline GGTGACCACAC & 14 & 12 & $125^{\star}$ & 28 & $\uparrow$ & TCCCCGTACAC & 62 & 78 & 26 & $0^{*}$ \\
\hline CTGACGACTGA & 9 & 9 & $59^{*}$ & 16 & $\uparrow$ & TCCCCGTACAG & 40 & 52 & 26 & $2^{*}$ \\
\hline TTGAGTCCTCC & 2 & 0 & $31^{*}$ & 10 & $\uparrow$ & CCGATGATCAG & 37 & 30 & 34 & $2^{*}$ \\
\hline ATGGGTCAAAG & 0 & 2 & $27^{*}$ & 11 & $\uparrow$ & ССССТАTTAAG & 30 & 25 & 21 & $1^{*}$ \\
\hline TCGGCTCCGAG & 2 & 1 & $27^{*}$ & 8 & $\uparrow$ & CATCATAAAAC & 33 & 30 & 22 & $1^{*}$ \\
\hline ACTGGGCAGGA & 0 & 0 & $15^{\star}$ & 9 & $\uparrow$ & CATCATAAAAG & 39 & 30 & 17 & $2^{\star}$ \\
\hline TTCCAAAGCAA & 0 & 1 & 13 & $83^{*}$ & $\uparrow$ & TCCTATTAAGC & 53 & 90 & 41 & $0^{*}$ \\
\hline GCGGAGATGAG & 5 & 0 & $22^{*}$ & $14^{*}$ & $\uparrow$ & TCCСТATTAAA & 39 & 37 & 23 & $1^{*}$ \\
\hline GGCGGGACCAC & 16 & 4 & $44^{*}$ & 7 & $\uparrow$ & TCССТАТTAAC & 29 & 31 & 21 & $1^{*}$ \\
\hline GATGCGCTTGT & 13 & 4 & $25^{*}$ & 3 & $\uparrow$ & ТСССТАТТААТ & 28 & 24 & 17 & $0^{*}$ \\
\hline GCAGCCAGGGC & 4 & 2 & $23^{*}$ & 3 & $\uparrow$ & CAACCATCATC & 99 & 51 & 80 & $6^{*}$ \\
\hline GTGGCGGTGGC & 1 & 0 & $14^{*}$ & 2 & $\uparrow$ & CAAAGATTAAA & 196 & 205 & 87 & $51^{*}$ \\
\hline TCCGGAGAAAA & 0 & 0 & 1 & $42^{*}$ & $\uparrow$ & ATGTTGGGCAG & 28 & 16 & 7 & $1^{*}$ \\
\hline TCCGGAGAAAG & 0 & 0 & 5 & $49^{*}$ & $\uparrow$ & GAAGCACACAG & 23 & 23 & 6 & $0^{*}$ \\
\hline GCCTGAATCAG & 1 & 1 & 9 & $82^{*}$ & $\uparrow$ & TCCCCATACAT & 12 & 20 & 3 & $0^{*}$ \\
\hline GGACAATTGTG & 0 & 0 & 2 & $19^{*}$ & $\uparrow$ & ТССССТАТTАА & 47 & 43 & 24 & $7^{*}$ \\
\hline TAGCTGTGTGG & 0 & 0 & 1 & $15^{\star}$ & $\uparrow$ & CATCATAAAAT & 32 & 32 & 10 & $1^{*}$ \\
\hline CAAGTAGATGA & 0 & 0 & 1 & $15^{\star}$ & $\uparrow$ & GCCCTATTAAG & 15 & 19 & 9 & $0^{\star}$ \\
\hline CAGTCAGAAAG & 0 & 0 & 0 & $14^{*}$ & $\uparrow$ & TCCATATTAAG & 16 & 22 & 5 & $1^{*}$ \\
\hline CAGCTAGTTGC & 0 & 0 & 1 & $22^{*}$ & $\uparrow$ & TCCGCGTACAT & 15 & 20 & 5 & $1^{*}$ \\
\hline AAGGAATAAGC & 2 & 7 & 12 & $31^{*}$ & $\uparrow$ & TCCCTATTAGG & 22 & 15 & 5 & $1^{*}$ \\
\hline GGCTAGATTTC & 3 & 2 & 11 & $24^{\star}$ & $\uparrow$ & TACCCGTACAT & 13 & 14 & 4 & $0^{*}$ \\
\hline TGTGATGTCAG & 0 & 0 & 2 & $14^{*}$ & $\uparrow$ & TTCTGGTTTGT & 55 & 71 & 27 & $10^{*}$ \\
\hline TAATCATCGAA & 8 & 3 & $1 \overline{3}$ & $28^{*}$ & $\uparrow$ & TCACTATTAAG & 11 & 19 & 13 & $0^{\star}$ \\
\hline TGGGAGATGCT & 2 & 0 & 9 & $15^{\star}$ & $\uparrow$ & TACCTATTAAG & 10 & 19 & 9 & $0^{*}$ \\
\hline CССTATTAAGC & 55 & 54 & $15^{*}$ & $0^{*}$ & $\downarrow$ & ТССССТАСАТС & 9 & 18 & 5 & $0^{*}$ \\
\hline CATCATAAAAA & 437 & 337 & $123^{*}$ & $5^{\star}$ & 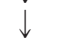 & TCCGTATTAAG & 18 & 26 & 11 & $3^{*}$ \\
\hline GCAGTGGGTAG & 238 & 500 & $95^{\star}$ & $55^{\star}$ & $\downarrow$ & TGCCTATTAAG & 16 & 23 & 11 & $2^{\star}$ \\
\hline TCACCGTACAT & 22 & 22 & $3^{*}$ & $0^{*}$ & $\downarrow$ & TCCCATTAAGC & 10 & 23 & 9 & $1^{*}$ \\
\hline GCGGAGAAGAA & 21 & 19 & $0^{*}$ & $0^{*}$ & $\downarrow$ & TCССТACTAAG & 14 & 25 & 7 & $2^{\star}$ \\
\hline СССТTТСАТАA & 107 & 104 & $18^{*}$ & $16^{\star}$ & $i$ & СTTAАСТСТGC & 15 & 25 & 10 & $2^{\star}$ \\
\hline CAATGCTGCCT & 32 & 20 & $2^{*}$ & 3 & $\downarrow$ & TCCCCCGTACA & 12 & 21 & 5 & $1^{*}$ \\
\hline TAGAGACTGCC & 23 & 58 & $2^{*}$ & $14^{\star}$ & $\downarrow$ & TCGCCGTACAT & 12 & 19 & 5 & $1^{*}$ \\
\hline AAAAATCATCG & 41 & 49 & $4^{*}$ & 48 & $\downarrow$ & TTCCTATTAAG & 16 & 23 & 12 & $3^{*}$ \\
\hline GTGACCACGGG & 61 & 40 & $9^{*}$ & 30 & $\downarrow$ & TCCCGTACATC & 10 & 13 & 2 & $0^{*}$ \\
\hline TCССТATAAGC & 199 & 298 & $115^{\star}$ & $0^{*}$ & $\downarrow$ & TCCСТTTAAGC & 4 & 13 & 2 & $0^{\star}$ \\
\hline TGTCAGGTGTC & 18 & 43 & $10^{*}$ & $0^{*}$ & $\downarrow$ & CATCATACATC & 21 & 22 & 4 & $3^{*}$ \\
\hline TCCCCGACATC & 17 & 48 & $8^{*}$ & $1^{*}$ & $\downarrow$ & TCССТATAAGA & 8 & 12 & 6 & $0^{*}$ \\
\hline TCTCCGTACAT & 36 & 63 & $12^{*}$ & $6^{\star}$ & $\downarrow$ & TCGCTATTAAG & 15 & 19 & 11 & $2^{*}$ \\
\hline TCCCTGTTAAG & 12 & 18 & $2^{*}$ & $0^{*}$ & $\downarrow$ & CCTATTAAAAG & 14 & 19 & 11 & $2^{\star}$ \\
\hline
\end{tabular}

I, intact; G, GDX; 3 h, DHT3h; 24 h, DHT24h.

*Significantly different $(P<0.05)$ from G. Arrows are used to show a simplified representation of the effects of DHT. When castration induces a significant change in expression level, a dash is used instead of an arrow. 


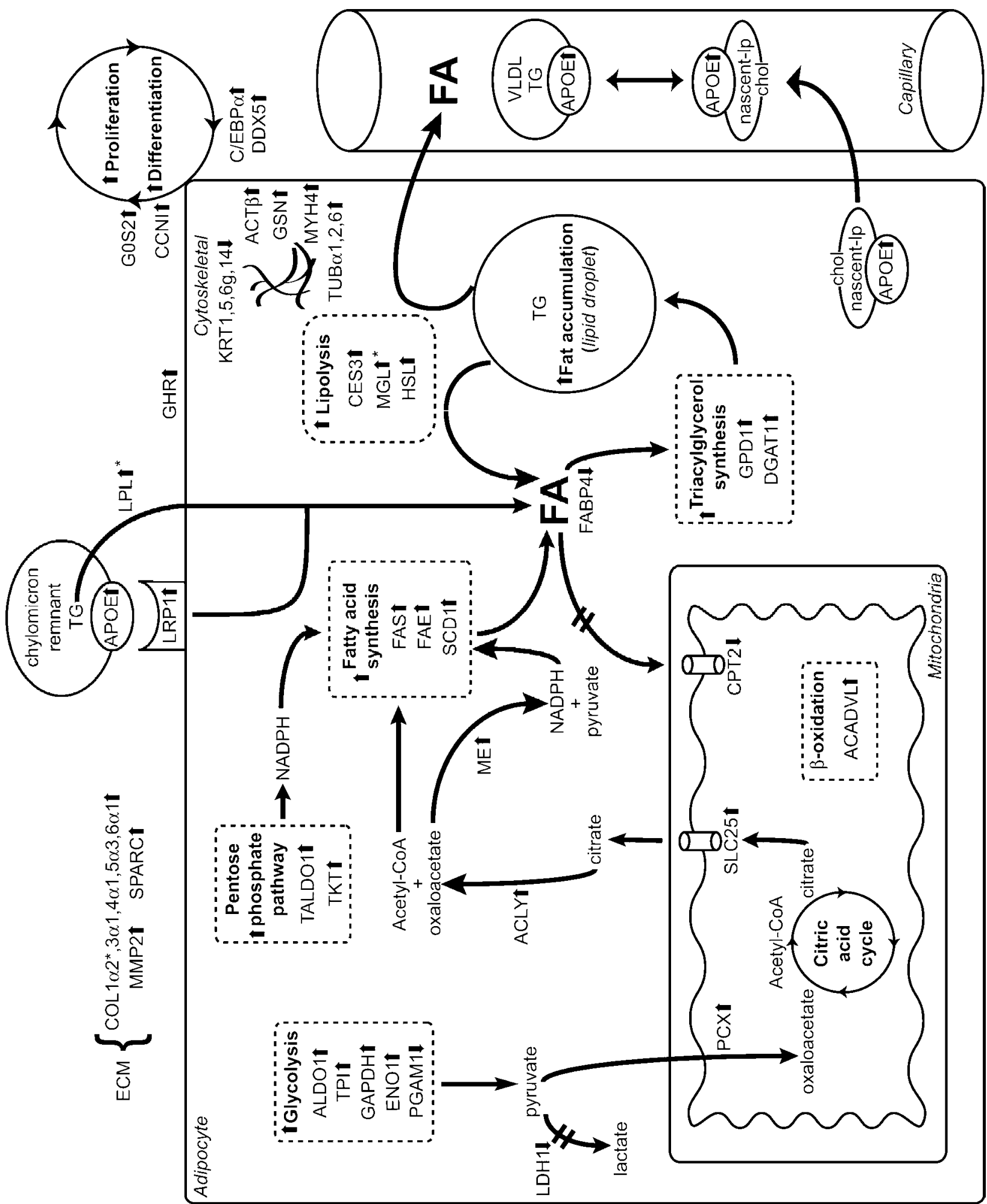


SAGE, we have characterized the effects of the nonaromatizable and most potent natural androgen, DHT, on the adipose tissue transcriptome. An overview of these data is presented by Fig. 1, which shows some of the changes mediated by the androgen on energy substrate pathways and adipocyte differentiation in male mice retroperitoneal adipose tissue.

The general upregulation of transcripts involved in glycolysis may lead to a greater production of pyruvate which does not seem to be directed to the production of ATP, since lactate dehydrogenase 1 A chain is downregulated. Thus, fuel for de novo fatty acid synthesis may be produced, and transcripts involved in de novo fatty acid synthesis machinery itself are upregulated. In fact, positive regulation by DHT of lipogenic enzymes such as ATP citrate lyase, malic enzyme and fatty acid synthase has already been observed in monkey prostates (Arunakaran et al. 1992). In addition, two transcripts coding for lipoprotein lipase (LPL) are upregulated (except one EST), as previously reported (Anderson et al. 2002). It should be mentioned that even if there is fatty acid synthesis, if the fat is not stored in the form of triacylglycerol, and if fat oxidation is stimulated, fat mass may decrease. In fact, there is an upregulation by DHT of GPD1 and DGAT1, which are involved in triacyglycerol synthesis.

The upregulation of transcripts involved in de novo fatty acid and triacylglycerol synthesis could reflect the differentiation of preadipocytes into adipocytes, since many of these genes are stimulated in the adipocyte-differentiation process (Mackall et al. 1976, Coleman et al. 1978). In addition, C/EBP alpha, which is a major factor involved in adipocyte differentiation and in the expression of adipocyte-specific genes (Gregoire et al. 1998), is upregulated. Moreover, the present data also show an upregulation of $\mathrm{DEAD} / \mathrm{H}$ (Asp-Glu-Ala-Asp/His) box polypeptide 5 by DHT. The expression of this gene has been associated with adipogenesis (Kitamura et al. 2001), and it has been identified among the transcripts associated with adipose tissue fattening in the cow (Oishi et al. 2000). Cell structure reorganization is necessary for the differentiation process (Croissandeau et al. 2002). Keratin (K) proteins gather in pairs of acidic and basic keratins to form intermediate filaments. For example, in the skin, K5 and K14 form heterodimers, and alteration of one of these two molecules leads to skin fragility (Schuilenga-Hut et al. 2003). The downregulation of these and other keratins in this study may affect adipocyte cell shape. Extracellular matrix (EGM) components, such as collagen types I, III, IV, V and VI, increase three- to sixfold under adipogenic conditions (Nakajima et al. 2002). Moreover, MMP-2 is also involved in adipocyte development, since it regulates the balance between ECM deposition and degradation. In fact, inhibition of MMP can block the adipocyte differentiation process (Croissandeau et al. 2002). Transcripts related to all these ECM components are upregulated by DHT in the present study. All these mechanisms can promote the adipocyte differentiation process. It should be mentioned that the stimulation by DHT of collagen type 1 in osteoblastic cells (Kasperk et al. 1996) and of MMP-2 in human prostate cancer cells (Liao et al. 2003) has already been observed.

Figure 1 Overview of the effects of dihydrotestosterone on energy substrate pathways and adipocyte differentiation in retroperitoneal adipose tissue. Abbreviations: ACADVL, acyl-coenzyme A dehydrogenase very long chain; ACLY, ATP citrate lyase; ACT $\beta$, actin beta cytoplasmic; ALDO1, aldolase 1 A isoform; APOE, apolipoprotein E; CCNI, cyclin I; C/EBP $\alpha$, CCAAT/enhancer binding protein alpha; CES3, carboxylesterase 3; chol, cholesterol; COL $1 \alpha 2,3 \alpha 1,4 \alpha 1,5 \alpha 3,6 \alpha 1$, procollagen type I alpha 2, type III alpha 1, type IV alpha 1, type V alpha 3 , type VI alpha 1; CPT2, carnitine palmitoyltransferase 2; DDX5, DEAD/H (Asp-Glu-Ala-Asp/His) box polypeptide 5; DGAT1, diacylglycerol $O$-acyltransferase 1; ENO1, enolase 1 alpha nonneuron; ECM, extracellular matrix; FA, fatty acids; FABP4, adipocyte fatty acid-binding protein 4; FAE, fatty acyl elongase; FAS, fatty acid synthase; G0S2, G0/G1 switch gene 2; GAPDH, glyceraldehyde-3-phosphate dehydrogenase; GHR, growth hormone receptor; GPD1, glycerol-3-phosphate dehydrogenase 1 (soluble); GSN, gelsolin; HSL, hormone-sensitive lipase; KRT1,5,6 g,14, keratin genes 1, 5, $6 \mathrm{~g}$ and 14; LDH1, lactate dehydrogenase $1 \mathrm{~A}$ chain; LPL, lipoprotein lipase; LRP1, low-density lipoprotein receptor-related protein 1; ME, malic enzyme supernatant; MGL, monoglyceride lipase; MYH4, myosin heavy polypeptide 4 skeletal muscle; MMP2, matrix metalloproteinase 2; nascent-Ip, nascent lipoprotein; PCX, pyruvate carboxylase; PGAM1, phosphoglycerate mutase 1; SCD1, stearoyl-coenzyme A desaturase 1; SLC25, solute carrier family 25 (mitochondrial carrier; citrate transporter) member 1; SPARC, secreted acidic cysteine-rich glycoprotein; TALDO1, transaldolase 1; TG, triglyceride; TKT, transketolase; TPI, triosephosphate isomerase; TUB $\alpha 1,2,6$, EST tubulin alpha 1, 2 and 6; VLDL, very low-density lipoprotein. *Except one EST. 
Besides lipogenesis, transcripts involved in the lipolysis process are also upregulated. In fact, hormone-sensitive lipase and carboxylesterase 3, a lipase participating in the mobilization of fatty acids from the triacylglycerol content of adipose tissue (Dolinsky et al. 2001), are upregulated by DHT, while monoglyceride lipase is also upregulated (except one EST). On the other hand, the adipocyte complement-related protein, also known as adiponectin, is upregulated. Knockout of this gene revealed an increased $\beta$-oxidation in muscle and liver of mice (Ma et al. 2002). Furthermore, knockout of the aP2 gene, encoding for adipocyte FABP4, has indicated a defect in basal and stimulated lipolysis (Coe et al. 1999). The present study shows that the expression of this gene is downregulated by DHT. Finally, fatty acid coenzyme A ligase long chain 2, which activates long-chain fatty acids for both lipid synthesis and degradation via $\beta$-oxidation (Weiner et al. 1991), is upregulated by DHT, the most potent androgen.

As presented in Tables 2-8, the changes in androgen state affected all cell functions at various levels. In our previous study on the adipose tissue transcritpome under intact animal condition, many genes involved in the cell and organism defense were among the most highly expressed (Bolduc 2004 et al.). The present study shows that carbonic anhydrase 3, the most highly expressed gene in adipose tissue, is downregulated by DHT. It is still unclear why this gene is so highly expressed and what role it has in adipose tissue. In addition, the isoform carbonic anhydrase 5a is also downregulated. Generally, we have observed an upregulation by DHT of antioxidant proteins such as glutathione peroxidase 3 and 4, as well as superoxide dismutase 3 extracellular. Tags matching for the same gene or UniGene cluster were frequently found in the present study, particulary for the most abundant transcripts. For example, this was found for carbonic anhydrase 3. This may be partly explained by alternative polyadenylation cleavage site selection (Pauws et al. 2001) and alternative splicing (Mironov et al. 1999).

Analysis of all the data shows that various pathways are regulated by DHT in adipose tissue, and the gene expression profile changes induced by DHT suggest a promotion of fatty acid and triacylglycerol production as well as lypolysis in retroperitoneal adipose tissue. The equilibrium between these processes may bend on one side or the other, resulting in fat accumulation or fat loss. An in vitro study revealed that DHT could stimulate lipolysis through adenylate cyclase activation (Xu et al. 1990). However, it has been observed, in intact men, that DHT treatment increased visceral fat mass (Marin 1995). These findings on the acute effects of DHT seem to contradict the observations revealing a negative correlation between abdominal obesity and serum testosterone levels in men (Seidell et al. 1990, Zumoff et al. 1990, Tsai et al. 2000). In fact, testosterone treatment can reduce visceral fat mass and waist-hip ratio (WHR) in men (Marin et al. 1992, Marin 1995). Moreover, testosterone inhibited triacylglycerol uptake in abdominal adipose tissue of obese men (Marin et al. 1995). On the other hand, DHT had no significant effect on either WHR (Marin et al. 1995) or triacylglycerol uptake (Marin et al. 1995). Differential display PCR has already shown that testosterone and DHT have different effects on prostate gene expression (Avila et al. 1998). The different and sometimes opposite actions of testosterone and DHT may indicate that testosterone effects are mediated by a compound created via the aromatization process (Jensen 2000).

While DHT administration affected the expression of hundreds of genes, 7 days of gonadectomy affected only a few. In fact, only 13 classified transcripts were significantly differentially expressed between the intact and the GDX groups. Several of them, such as $\mathrm{NADH}$ dehydrogenase subunit 4, pheromone receptor V3R4 and three novel transcripts, showed an inverse pattern of expression in comparing the effect of castration and DHT injection. The tag CATG ATTTTCAGTTT, classified as a novel transcript, displayed a very sharp regulation by androgen modulation. The expression level of this tag changed from 7 in intact to 136 in GDX, falling back to 7 in DHT3h and rising to 115 in DHT24h. On the other hand, the expression of protamine 2, a transcript associated with chromatin condensation in sperm (Aoki \& Carrell 2003), could never be restored after castration. This gene may be a target of testosterone, which may have different effects from DHT on gene expression.

Several HRE possibilities were found in the promoter of the significantly differentially expressed transcripts, many of them being included in the $500 \mathrm{bp}$ upstream region of the transcription initiation start. Since the occurrence of a $6 \mathrm{bp}$ 
sequence by chance alone is equal to once each $4096 \mathrm{pb}$, this finding reinforces the idea that these genes are potentially regulated by DHT.

In conclusion, the present data suggest that the administration of DHT to GDX male mice promotes processes involved in glycolysis, fatty acid and triacylglycerol production, lipolysis and cell shape reorganization, as well as cell proliferation and differentiation in retroperitoneal adipose tissue. Moreover, the steroid hormone affected almost all aspects of cell function by modulating hundreds of transcripts. In addition, many of those correspond to novel transcripts.

\section{Acknowledgements}

We would like to thank Nicolas Lafond, Dr André Boivin, and all the research assistants involved in the ATLAS project for their skillful technical assistance. This work was supported by Genome Québec and Genome Canada.

\section{References}

Adams MD, Kerlavage AR, Fleischmann RD, Fuldner RA, Bult CJ, Lee NH, Kirkness EF, Weinstock KG, Gocayne JD, White O et al. 1995 Initial assessment of human gene diversity and expression patterns based upon 83 million nucleotides of cDNA sequence. Nature 377 3-174.

Anderson LA, McTernan PG, Harte AL, Barnett AH \& Kumar S 2002 The regulation of HSL and LPL expression by DHT and flutamide in human subcutaneous adipose tissue. Diabetes Obesity and Metabolism 4 209-213.

Aoki VW \& Carrell DT 2003 Human protamines and the developing spermatid: their structure, function, expression and relationship with male infertility. Asian Fournal of Andrology 5 315-324.

Arunakaran J, Balasubramanian K, Srinivasan N, Aruldhas MM \& Govindarajulu P 1992 Interaction of androgens and prolactin on prostatic enzymes of the pyruvate-malate cycle involved in lipogenesis in castrated mature monkey, Macaca radiata. Cytobios 70 33-40.

Avila DM, Fuqua SA, George FW \& McPhaul MJ 1998 Identification of genes expressed in the rat prostate that are modulated differently by castration and finasteride treatment. Fournal of Endocrinology 159 403-411.

Bolduc C, Larose M, Lafond N, Yoshioka M, Rodrigue MA, Morissette J, Labrie C, Raymond V \& St-Amand J 2004 Adipose tissue transcriptome by serial analysis of gene expression. Obesity $12750-757$.

Bray GA 1985 Complications of obesity. Annals of Internal Medicine 103 1052-1062.

Calle EE, Rodriguez C, Walker-Thurmond K \& Thun MJ 2003 Overweight, obesity, and mortality from cancer in a prospectively studied cohort of U.S. adults. New England Fournal of Medicine $\mathbf{3 4 8}$ 1625-1638.

Coe NR, Simpson MA \& Bernlohr DA 1999 Targeted disruption of the adipocyte lipid-binding protein (aP2 protein) gene impairs fat cell lipolysis and increases cellular fatty acid levels. Fournal of Lipid Research 40 967-972.

Coleman RA, Reed BC, Mackall JC, Student AK, Lane MD \& Bell RM 1978 Selective changes in microsomal enzymes of triacylglycerol phosphatidylcholine, and phosphatidylethanolamine biosynthesis during differentiation of 3T3-L1 preadipocytes. Fournal of Biological Chemistry 253 7256-7261.

Croissandeau G, Chretien M \& Mbikay M 2002 Involvement of matrix metalloproteinases in the adipose conversion of 3T3-L1 preadipocytes. Biochemical Journal 364 739-746.

Despres JP, Moorjani S, Lupien PJ, Tremblay A, Nadeau A \& Bouchard C 1990 Regional distribution of body fat, plasma lipoproteins, and cardiovascular disease. Arteriosclerosis 10 497-511.

Dolinsky VW, Sipione S, Lehner R \& Vance DE 2001 The cloning and expression of a murine triacylglycerol hydrolase cDNA and the structure of its corresponding gene. Biochimie et Biophysica Acta $1532162-172$.

Gregoire FM, Smas CM \& Sul HS 1998 Understanding adipocyte differentiation. Physiology Reviews 78 783-809.

Jensen MD 2000 Androgen effect on body composition and fat metabolism. Mayo Clinic Proceedings 75 (Suppl) S65-68; discussion S68-69.

Kasperk CH, Faehling K, Borcsok I \& Ziegler R 1996 Effects of androgens on subpopulations of the human osteosarcoma cell line SaOS2. Calcified Tissue International 58 376-382.

Kenzelmann M \& Muhlemann K 1999 Substantially enhanced cloning efficiency of SAGE (serial analysis of gene expression) by adding a heating step to the original protocol. Nucleic Acids Research 27 917-918.

Kissebah AH, Freedman DS \& Peiris AN 1989 Health risks of obesity. Medical Clinics of North America 73 111-138.

Kitamura A, Nishizuka M, Tominaga K, Tsuchiya T, Nishihara T \& Imagawa M 2001 Expression of p68 RNA helicase is closely related to the early stage of adipocyte differentiation of mouse 3T3-L1 cells. Biochemical and Biophysical Research Communications 287 435-439.

Lash AE, Tolstoshev CM, Wagner L, Schuler GD, Strausberg RL, Riggins GJ \& Altschul SF 2000 SAGEmap: a public gene expression resource. Genome Research 10 1051-1060.

Liao X, Thrasher JB, Pelling J, Holzbeierlein J, Sang QX \& Li B 2003 Androgen stimulates matrix metalloproteinase-2 expression in human prostate cancer. Endocrinology 144 1656-1663.

Ma K, Cabrero A, Saha PK, Kojima H, Li L, Chang BH, Paul A \& Chan L 2002 Increased beta-oxidation but no insulin resistance or glucose intolerance in mice lacking adiponectin. Fournal of Biological Chemistry 277 34658-34661.

Mackall JC, Student AK, Polakis SE \& Lane MD 1976 Induction of lipogenesis during differentiation in a 'preadipocyte' cell line. Fournal of Biological Chemistry 251 6462-6464.

Marin P 1995 Testosterone and regional fat distribution. Obesity Research 3 (Suppl 4) 609S-612S.

Marin P, Krotkiewski M \& Bjorntorp P 1992 Androgen treatment of middle-aged, obese men: effects on metabolism, muscle and adipose tissues. European Fournal of Medicine 1 329-336.

Marin P, Oden B \& Bjorntorp P 1995 Assimilation and mobilization of triglycerides in subcutaneous abdominal and femoral adipose tissue in vivo in men: effects of androgens. Fournal of Clinical Endocrinology and Metabolism $\mathbf{8 0} 239-243$.

Mironov AA, Fickett JW \& Gelfand MS 1999 Frequent alternative splicing of human genes. Genome Research 9 1288-1293.

Nakajima I, Muroya S, Tanabe R \& Chikuni K 2002 Extracellular matrix development during differentiation into adipocytes with a unique increase in types V and VI collagen. Biology of the Cell $\mathbf{9 4}$ 197-203.

Nelson CC, Hendy SC, Shukin RJ, Cheng H, Bruchovsky N, Koop BF \& Rennie PS 1999 Determinants of DNA sequence specificity of the androgen, progesterone, and glucocorticoid receptors: 
evidence for differential steroid receptor response elements. Molecular Endocrinology 13 2090-2107.

Novak JP, Sladek R \& Hudson TJ 2002 Characterization of variability in large-scale gene expression data: implications for study design. Genomics 79 104-113.

Oishi M, Taniguchi Y, Nishimura K, Yamada T \& Sasaki Y 2000 Characterisation of gene expression in bovine adipose tissue before and after fattening. Animal Genetics 31 166-170.

Pauws E, van Kampen AH, van de Graaf SA, de Vijlder JJ \& Ris-Stalpers C 2001 Heterogeneity in polyadenylation cleavage sites in mammalian mRNA sequences: implications for SAGE analysis. Nucleic Acids Research 29 1690-1694.

Schena M, Shalon D, Davis RW \& Brown PO 1995 Quantitative monitoring of gene expression patterns with a complementary DNA microarray. Science 270 467-470.

Schuilenga-Hut PH, Vlies P, Jonkman MF, Waanders E, Buys CH \& Scheffer H 2003 Mutation analysis of the entire keratin 5 and 14 genes in patients with epidermolysis bullosa simplex and identification of novel mutations. Human Mutations 21447.

Seidell JC 2000 Obesity, insulin resistance and diabetes - a worldwide epidemic. British Fournal of Nutrition 83 (Suppl 1) S5-8.

Seidell JC, Bjorntorp P, Sjostrom L, Kvist H \& Sannerstedt R 1990 Visceral fat accumulation in men is positively associated with insulin, glucose, and C-peptide levels, but negatively with testosterone levels. Metabolism 39 897-901.

Sheehan MT \& Jensen MD 2000 Metabolic complications of obesity. Pathophysiologic considerations. Medical Clinics of North America 84 363-385, vi.

Sjostrom L, Smith U, Krotkiewski M \& Bjorntorp P 1972 Cellularity in different regions of adipose tissue in young men and women. Metabolism 21 1143-1153.

St-Amand J, Okamura K, Matsumoto K, Shimizu S \& Sogawa Y 2001 Characterization of control and immobilized skeletal muscle: an overview from genetic engineering. FASEB foumal $\mathbf{1 5}$ $684-692$.
Tsai EC, Boyko EJ, Leonetti DL \& Fujimoto WY 2000 Low serum testosterone level as a predictor of increased visceral fat in Japanese-American men. International Fournal of Obesity-Related Metabolic Disorders 24 485-491.

Vague J 1956 The degree of masculine differentiation of obesities: a factor determining predisposition to diabetes, atherosclerosis, gout, and uric calculous disease. American Fournal of Clinical Nutrition 4 20-34.

Velculescu VE, Zhang L, Vogelstein B \& Kinzler KW 1995 Serial analysis of gene expression. Science 270484487.

Velculescu VE, Zhang L, Zhou W, Vogelstein J, Basrai MA, Bassett DE Jr, Hieter P, Vogelstein B \& Kinzler KW 1997 Characterization of the yeast transcriptome. Cell 88 243-251.

Virlon B, Cheval L, Buhler JM, Billon E, Doucet A \& Elalouf JM 1999 Serial microanalysis of renal transcriptomes. PNAS 96 15286-15291.

Weiner FR, Smith PJ, Wertheimer S \& Rubin CS 1991 Regulation of gene expression by insulin and tumor necrosis factor alpha in 3T3-L1 cells. Modulation of the transcription of genes encoding acyl-CoA synthetase and stearoyl-CoA desaturase-1. Fournal of Biological Chemistry 266 23525-23528.

Xu X, De Pergola G \& Bjorntorp P 1990 The effects of androgens on the regulation of lipolysis in adipose precursor cells. Endocrinology 126 1229-1234.

Zumoff B, Strain GW, Miller LK, Rosner W, Senie R, Seres DS \& Rosenfeld RS 1990 Plasma free and non-sex-hormone-binding-globulin-bound testosterones are decreased in obese men in proportion to their degree of obesity. Journal of Clinical Endocrinology and Metabolism 71 929-931.

Received 14 May 2004

Accepted 25 June 2004 